\title{
DAS INCERTEZAS E DA COMPLEXIDADE DA EDUCAÇÃO NO SÉCULO XXI
}

\section{Francisco Renato Lima ${ }^{1}$}

\section{Resenha}

MORIN, Edgar. Os sete saberes necessários à educação do futuro. 2. ed. São Paulo: Cortez; Brasília, DF: UNESCO, 2011.

\section{Credenciais do autor}

\section{Edgar Morin}

Formado em Direito, História e Geografia, realizou estudos em Filosofia, Antropologia, Sociologia e Epistemologia. Pesquisador emérito do CNRS (Centre National de la Recherche Scientifique). Autor de mais de trinta livros, entre eles: $O$ método (6 volumes), Introdução ao pensamento complexo, Ciência com consciência e Os sete saberes necessários para a educação do futuro. É considerado um dos principais pensadores contemporâneos e um dos principais teóricos da complexidade, educação e epistemologia.

\section{Resumo da obra}

“Os sete saberes necessários à educação do futuro", é uma obra escrita em 1999. Nesta oportunidade, a UNESCO (Organização das Nações Unidas para a Educação, a Ciência e a Cultura) solicitou a Edgar Morin, que escrevesse um texto/documento sistematizando uma série de conhecimentos que respondessem às futuras demandas da educação, partindo do contexto o qual estavam vivenciando. Desafiado pela proposta, o autor postula alguns princípios que deveriam inspirar o educador em sua prática, considerando a complexidade dos problemas inerentes à transição do século XX para o XXI, e que somente por meio de 'estudos de caráter inter-poli-transdisciplinar poderiam resultar em análises satisfatórias de tais complexidades'. E é a isto que ele propõe em todo o texto.

O livro está dividido em sete partes, que dialogam entre si, na construção da tessitura macro da proposta. O autor inscreve sua ideia na dialética das contradições de um tempo de mudanças paradigmáticas no tempo e no espaço, a pensar, por exemplo: na intensificação das

\footnotetext{
${ }^{1}$ Graduado em Pedagogia (FSA). Especialista em Neuropsicopedagogia Clínica e Educação Especial (IESM). Especialista em Docência para o Ensino Superior (IESM). Especialista em Educação a Distância (UNOPAR). Especialista em Docência no Ensino Superior (FSA). Mestre em Letras - Estudos da Linguagem (UFPI). Com experiência docente na rede pública e privada de ensino básico e superior. Email: fcorenatolima@hotmail.com
} 
mídias da informação e no aceleramento do processo de globalização, entre outras mudanças, as quais implicam diretamente nos domínios da educação.

No primeiro capítulo: "As cegueiras do conhecimento: o erro e a ilusão", Morin alerta que a educação, embora se aproprie do discurso de transmissora do conhecimento, continua cega quanto a importância do conhecimento humano, como instrumento valorativo da vida em esfera global. Aponta para o erro e a ilusão como ameaça ao conhecimento sistematizado pelas ciências. Os erros são de três descendências: os erros mentais, uma vez que a mente é um campo potencial para mentiras; os erros intelectuais, posto que as teorias se fecham em si mesmas e não reconhecem aquilo que não lhe convém; e os erros da razão, os quais referem-se aqueles que desconsideram a subjetividade, a afetividade e a vida humana.

Em decorrência disso, surgem as cegueiras paradigmáticas, as quais se sustentam por constituir dicotomias axiomáticas, entre conceitos, comandos, discursos, crenças e convicções que impõe forças normatizadoras por meio de doutrinas e ideologias difundidas socialmente. Considera também a questão da noosfera, a qual faz parte do ser humano, relacionada às coisas do espírito, e que, portanto, não podem ser desconsideradas, visto que ao tratar do conhecimento, deve-se ter consciência do inesperado e das incertezas, até mesmo aquelas que as teorias e as ideias consagradas, acabam por não acolhê-las plenamente.

O segundo capítulo: "Os princípios do conhecimento pertinente", discute acerca da relação existente entre conhecimentos em esfera global e que interferem em esferas locais, e que este entendimento pressupõe uma adequação cognitiva, posto que embora se vivencie problemas de ordem multidisciplinar, transversal, global e planetários, as ciências estão cada vez mais compartimentadas e divididas em especializações que ignoram a relação das partes como fundamental para a construção do todo. Esse problema torna invisível o contexto: o conhecimento se dá em contextos distintos e determinados sócio historicamente; o global: as diversas partes que compõem o todo; o multidimensional: o ser humano em seus aspectos psíquicos, sociais, biológicos, afetivos e racionais, por exemplo; e o complexo: envolve a interdependência entre os elementos constituintes do todo da complexidade.

Em contrapartida a essa fragmentação, o autor propõe a inteligência geral, que seria uma forma de compreender, de forma articulada, toda essa complexidade, organizando o conhecimento de conjuntos, para casos particulares, específicos, superando as antinomias (as quebras existentes entre as especializações disciplinares), preocupando-se, portanto, com problemas essenciais, que para a solução, dependem do rompimento com essa disjunção e especialização fechada, a redução do complexo ao simples e a falsa racionalidade imperiosa. 
O capítulo três, intitulado: "Ensinar a condição humana", segue a mesma linha de raciocínio do anterior, apontando que o ser humano é um ser físico, biológico, cultural, psíquico, social e histórico, e que por isso, deve ser tratado em sua totalidade, considerando-o próximo ao universo, e não o contrário, como muitas vezes, a segmentação do saber em disciplinas isoladas tem feito. Assim, ao tratar desse ser humano, é preciso considerar a condição cósmica, relacionada à ideia de Universo em expansão contínua; a condição física, uma vez que a vida é parte de uma atmosfera concreta; a condição terrena, posto que a sobrevivência humana dependa diretamente de sua relação de respeito com a biosfera terrestre; e a condição humana, a qual implica o reconhecimento do homem como um ser que se constrói desde o nascimento, em relação com a cultura, os saberes e fazeres adquiridos.

Sob a responsabilidade da educação está o fato de que a unidade da espécie humana não apague sua diversidade, e que a sua diversidade não apague sua diversidade. Ambas devem completar-se nas esferas individual e social que fazem parte do universo das culturas, considerando-se que o homem da cultura é o mesmo da afetividade, posto a complexidade e subjetividade, inerentes a razão de existência da espécie humana.

Em: "Ensinar a identidade terrena", o quarto capítulo, aponta para a necessidade de se ensinar o homem a relacionar-se com o planeta, levando-se em consideração as adversidades da era planetária. O mundo vive um estágio avançado de desenvolvimento econômico e globalização que afeta o planeta, por meio de cadeias produtivas de degradação aos subsídios naturais. Essa problemática tem deixado marcas de destruição, a herança de uma morte anunciada que destrói a modernidade. É preciso que o homem - filho da terra -, seja educado no sentido de respeitá-la e superar as contradições das forças que aprisionam, levam a morte e a servidão. Somente assim, a raça humana construirá uma identidade consciente de seu papel terreno, em respeito a pátria e a preservação da própria espécie.

O capítulo cinco: "Enfrentar as incertezas", discute sobre as fragilidades do ser humano, o qual não está preparado para conviver com as incertezas. Ao longo da história da humanidade, as ciências têm reforçado essa questão, por apresentar, muitas vezes, a garantia de certezas. Fato que tem mudado no contexto do século XX, uma vez que a própria ciência tem se dado conta da perda do controle sobre o futuro, o imprevisto.

Diante disso, a escola precisa ensinar a conviver com um mundo de incertezas que envolvem a realidade e o conhecimento científico, doutrinário e dogmático. Essa dúvida permanente envolve a ecologia da ação, a qual implica decisão, escolha e aposta no universo das interações humanas que desenvolve a sua volta, espaço no qual se encontra o aleatório, o acaso, o inesperado, o imprevisto e as transformações repentinas. Isso implica o desafio de estar 
consciente de apostas contidas em cada decisão e a adoção de estratégias que modifiquem os contratempos e as ameaças da destruição do progresso da humanidade.

No capítulo seis, intitulado: "Ensinar a compreensão", o autor segue a linha de raciocínio, e acrescenta que o atual estado egocentrismo, etnocentrismo cultural, de barbárie e desrespeito vivido no mundo é decorrente da falta de diálogo que geraria o entendimento e a compreensão entre os homens. Vive-se em estado de guerra, disputa e oposição de forças, que só distanciam a raça humana de um futuro harmonioso.

O autor considera que há duas compreensões: a intelectual ou objetiva, que perpassa pela inteligibilidade e pela lógica das explicações racionais; e a compreensão humana intersubjetiva, que vai além da mera explicação, mas exige o conhecimento do sujeito sobre si mesmo para poder compreender o outro, através de um processo de identificação e reconhecimento. Nesse percurso, a educação é chamada a resolver os obstáculos que alimentam a incompreensão, promovendo a ética do compreender desinteressado, o bem estar entre o subjetivo e o objetivo, a prática introspectiva de autoexame como forma de descobrir e superar as próprias fraquezas, a consciência da complexidade humana que comporta a abertura subjetiva para o outro e a tolerância entre as culturas.

No último capítulo: “A ética do gênero humano", o autor propõe a ética como princípio basilar da relação indivíduo x sociedade x espécie, de modo que deve haver uma relação de igualdade no controle entre indivíduo e sociedade, uma vez que são inseparáveis e inexistem isoladamente. O autor postula o termo 'antropoética', ao referir-se a esperança na completude da humanidade consciente e cidadã em sua relação com o planeta, por meio de ações democráticas e empenhadas em conciliar as adversidades que fazem parte da complexidade terrestre e assim, ter melhores homens e mulheres, construindo-se como tais na mais plena forma de respeito entre os gêneros da raça humana, que é uma só.

\section{Conclusões do autor da obra}

O autor assume ao longo da obra, o compromisso de pensar a educação como proposta de mudança, um caminho alternativo para a transformação social, política e cultural da humanidade, e para tanto, apresenta alternativas, em forma de saberes, os quais refletem e retratam realidades de ensino de todo o mundo. A partir desse comando, ele sequencia suas ideias de modo a concluí-las (ou não concluí-las, propositalmente) ao final de cada capítulo, de tal modo que, ao final do texto não estabelece uma marca textual-argumentativa denominada de ‘conclusão' ou 'considerações finais'; sequer fornece uma bibliografia. Muito pelo contrário, lança 
o desafio e o convite de que sua leitura seja encarada como parte de um processo de formação de opinião, na realização de leituras individuais, heterogêneas, nas quais se sobressaia a subjetividade do sujeito leitor, o qual enunciará e compreenderá a partir do lugar social de onde se situa, em um processo de construção e ampliação dos sentidos sobre sua própria ação no meio social.

\section{Críticas do resenhista}

As ideias apresentadas nesta obra podem ser compreendidas como um marco representativo de uma preocupação em esfera global e mundial, uma vez que foi solicitada pela UNESCO, ao discutir sobre os problemas e os dilemas que estão sob o crivo educacional, e que convergem para a necessidade de repensar o ensino, a prática docente e a ação educativa como um todo, de modo a alcançar avanços, sobretudo, na formação da pessoa humana.

O autor utiliza-se de uma linguagem acessível, porém muitas vezes, aproxima-se da prolixidade, considerando a repetição e a redundância nas ideias apresentadas ao longo dos capítulos, que em muito se assemelham; entretanto, este é um fato que também pode ser visto como positivo, por possibilitar a manutenção de um tópico coesivo e consistência das ideias.

Moran apresenta uma obra fundamental para a compreensão da educação no contexto dos séculos XX e XXI. Para a época de seu lançamento, no ano de 1999 - há quase 20 anos suas ideias apresentavam-se muito pertinentes à ideia de futuro que vislumbravam, partindo da realidade vivida naquele contexto; porém hoje, considerando-se os adventos da contemporaneidade, entende-se que, muitos atendem ao que o autor alertou. Muitas dessas ideias encontram-se, de certo modo, superadas, necessitando serem revistas, buscando atender a lógica das rápidas demandas que demarcam o atual contexto da hipermodernidade ${ }^{1}$, o qual trouxe novas configurações e necessidades de constante revisão acerca do dito e do vivido, principalmente dos fatos que envolvem a educação, considerando-se seu caráter dinâmico e plurifacetado.

O fato é que as teorias são construídas a partir de um tempo e de um contexto, e deste modo, com o passar dos tempos, mesmo que acabem não dando conta de novos fatos e fenômenos, elas não envelhecem, mas tornam-se maduras e possíveis de serem ampliadas e repensadas, constituindo-se como um marco, para o qual deverá ser sempre olhado e pensado na articulação entre o passado, o presente e o futuro.

\footnotetext{
${ }^{1}$ A utilização desse termo parte da leitura de Rojo; Barbosa (2015), quando o utilizam para referir-se às mudanças pelas quais o mundo passou; ocasionadas pela presença de diferentes fenômenos e tecnologias, que acarretam novos letramentos, multiletramentos, possibilitando, portanto, novas formas de interação social e construção de sentidos. Segundo as autoras, baseadas em Lipovetsky (2004) e Charles (2009), esse termo, "procura salientar não a superação, mas a radicalização da modernidade" (p. 116)
}

Referência: ROJO, Roxane; BARBOSA, Jacqueline P. Hipermodernidade, multiletramentos e gêneros discursivos. São Paulo: Parábola, 2015. 


\section{Indicações do resenhista}

Considerando-se os posicionamentos do autor e também, as críticas às suas valiosas ideias, ainda assim, torna-se fundamental apontar para a importância de sua leitura, por todos aqueles que estão envolvidos com a educação, seja em espaço escolar ou educacional. Sua discussão deve perpassar os caminhos dos processos de formação de professores, desde a graduação a pós-graduação (especialização, mestrado e doutorado), a título de ser uma possibilidade de conhecer a referida obra, que abre caminhos para uma discussão sobre a necessidade de melhorias nas práticas educativas de todos os profissionais da educação, desde os atuantes na educação infantil ao ensino superior, na medida em que todas estas etapas lidam com sujeitos, em suas instâncias de aprender e ensinar mutuamente. 